\title{
Diabetic Eye Disease Related Knowledge, Attitudes and Practices among Physicians in Nepal
}

\author{
Eli Pradhan ${ }^{1}$, Anadi Khatri ${ }^{2}$, Jasmeen Tuladhar ${ }^{3}$, Dina Shrestha ${ }^{4}$ \\ ${ }^{1}$ Consultant Medical Retina, Tilganga Institute of Ophthalmology, Kathmandu,Nepal \\ ${ }^{2}$ Consultant Vitreo-Retinal Surgeon, Birat Eye Hospital, Biratnagar, Nepal \\ ${ }^{3}$ Consultant Endocrinologist, Korean Nepal Friendship Hospital, Bhaktpur,Nepal \\ ${ }^{4}$ Consultant Endocrinologist, Norvic Interantional Hospital, Kathmandu, Nepal
}

\begin{abstract}
\section{Background:}

Awareness of diabetic retinopathy amongst general physicians is a major factor for the prevention of diabetes-related ocular complications. They are most often the first line of contact of diabetic patients and their knowledge and attitude are the principal indicators of their level of awareness.

\section{Methods:}

This cross-sectional study was conducted in Kathmandu and is based on a structured questionnaire referring to Diabetic retinopathy formulated on Guideline for Conducting a Knowledge, Attitude and Practice Study by information, Education, and Communication expert.The questionnaire comprised of 18 questions and 45 physicians were enrolled. Significant differences and associations were determined by values of $\mathrm{P}<0.05$.
\end{abstract}

\section{Results:}

All of the physicians (100\%) were aware that diabetes can damage the eye and can cause visual impairment. Most of them agreed that patients with diabetes should be sent for ophthalmic evaluations with majority mandating an immediate evaluation after the diagnosis. The majority $(98 \%)$ of physicians disagreed that eye examination was required only once the vision was affected. Only $56 \%$ of the physicians agreed

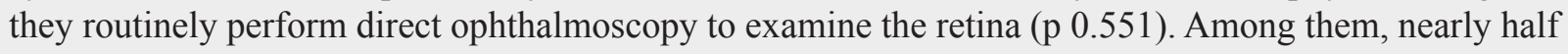
$(44 \%)$ reported not knowing the importance of dilating the pupil.$(p=0.69)$.

\section{Conclusions:}

The study shows a good level of diabetic retinopathy awareness and knowledge with positive attitudes toward the importance of diabetes care. At the same time, it has found that practice level despite good knowledge and attitude to be below average among the physicians who are managing diabetic patients.

Key Words: Knowledge, Attitude, Practice, Diabetes, Nepal, Diabetic Retinopathy

\section{Introduction:}

Diabetes mellitus has established itself as a fastest emerging epidemic globally. ${ }^{1}$ It is a vicious pathology affecting the macro and the microvascular components of different target organs. As a result,

Corresponding Author: Dr.Anadi Khatri, Department of Vitreo-Retina Disease and Surgery, Birat Eye Hospital, Biratnagar, Nepal, Phone no: 9779841767205, Email:anadikc (a)gmail.com it has climbed upthe ranking to also become one of the top causes of vision loss. ${ }^{2}$

In 2017, nearly half a billion people are estimated to be living with diabetes withlow and middleincome countries carry almost $80 \%$ of the diabetes burden. ${ }^{3}$ this is almost quadruple the number within a period of around 35 years but reports suggest we are a long way from achieving a control. Large 
Diabetic Eye Disease Related KAP among Physicians...

Jour of Diab and Endo Assoc of Nepal 2018; 2 (2):(26-36)

meta-analysis shows that roughly $50 \%$ of people with diabetes still remain undiagnosed. ${ }^{4}$ Despite advancements in technology and investigative methods for early diagnosis and treatment, nearly $75 \%$ of them are living in less economically developed countries where the equipment and treatment facilities are limited. Indian subcontinent and China account for nearly $45 \%$ of the burden. ${ }^{1}$ Diabetic retinopathy (DR) should never be undermined. It is the most common complication of diabetes and can lead to irreversible blindness if not identified early ${ }^{5}$ Depending upon the severity , this can range screening intervals of 1 year to 6 months and have proven effective for early discovery and management. ${ }^{3,4,6-9}$ Besides diabetic retinopathy, diabetic patients are also more prone to develop cataracts, glaucoma and fluctuating refractive errors. ${ }^{10-12}$

This success story is however different in developing countries. ${ }^{13-17}$ The primary care physicians are often the first medical personnel for patients with diabetes. The knowledge of the attending physicians regarding diabetic retinopathy is crucial as they are the main source of referrals for these patients to ophthalmologists. Various studies around the world have been done to access the diabetic eye disease awareness among physicians. ${ }^{18-23}$ Even in resourcerichsettings, many of these studies have suggested that the knowledge and awareness of physicians about diabetic retinopathy is inadequate and have recommended more robust training. ${ }^{20,24}$

Most of diabetes-relatedKAP studies in Nepal have focused on patientswith DM. One of the studies from Western Nepal showed KAP scores of the diabetic patients to be low. ${ }^{25}$ Another KAP study from Kathmandu showed 33\% had satisfactory knowledge about diabetes and $17.6 \%$ reported low. ${ }^{26}$ Another study done in Nepal regarding knowledge of diabetic retinopathy among patients by Thapa $\mathrm{R}$ et al ${ }^{27}$ concluded that nearly two-fifths of the patients had no awareness that diabetes could affect the eye which could result in blindness and only $50 \%$ of who were aware of DR claimed to have received information from physicians.

We do not have any data on the current status of this matter in amongst physician Nepal.The gravity of this problem is yet to be determined.This study aims aim to evaluate the current knowledge, awareness, and practices about DR among physicians in Nepal treating patients with diabetes. We expect the results will help us address "loopholes" and to construct efficient strategies to strengthen eye care of diabetic patients.

\section{Methodology:}

We conducted this cross-sectional study in Kathmandu on the 2nd day of "SAARC Diabetes 2016", on 10th September, in Kathmandu and included 45 physicians. The study is based on a structured questionnaire referring to Diabetic retinopathy.This study was performed with consent from participating physicians in compliance with the Declaration of Helsinki and maintains the confidentiality of the participants. A set of questionnaire formulated based on Guideline for Conducting a Knowledge, Attitude and Practice (KAP) Study by Kaliyaperumal K (I.E.C. Expert) ${ }^{28}$ the questionnaire comprised of 18questions in 3 sections on knowledge, attitude, and practices.

Physicians involved in the care of patients with diabetes (registered hospital physicians, general practitioners) working at different tertiary health centers in Nepal were asked to fill the questionnaire. Data were coded and entered into "Statistical Analysis" by Statistical Program for Social Sciences (SPSS) version 20 (IBM SPSS Inc.) and were analyzed using frequencies and percentage. Continuous variables were summarized using mean, percentile, range, and standard deviation. Significant differences and associations were determined by values of $\mathrm{P}<0.05$.Chi-square / Fisher exact test was used wherever applicable.

The written and informed consent from all the participants was taken and the confidentiality of the participants maintained.

\section{Results:}

We evaluated a total of 45 physicians who were involved in the care of patients with diabetes (registered hospital physicians general practitioners 
and endocrinologists) working at different tertiary health centers in Nepal. Twenty(22.4\%) of the physicians worked in government hospitals, twenty one (46\%) at a private hospital, three (7\%) at NGO run hospitals and one (2\%) at the community-basedhospital.(Figure 1) The mean number of patients evaluated by each physician was 16.3(SD 4.7) daily.

\section{Working place}

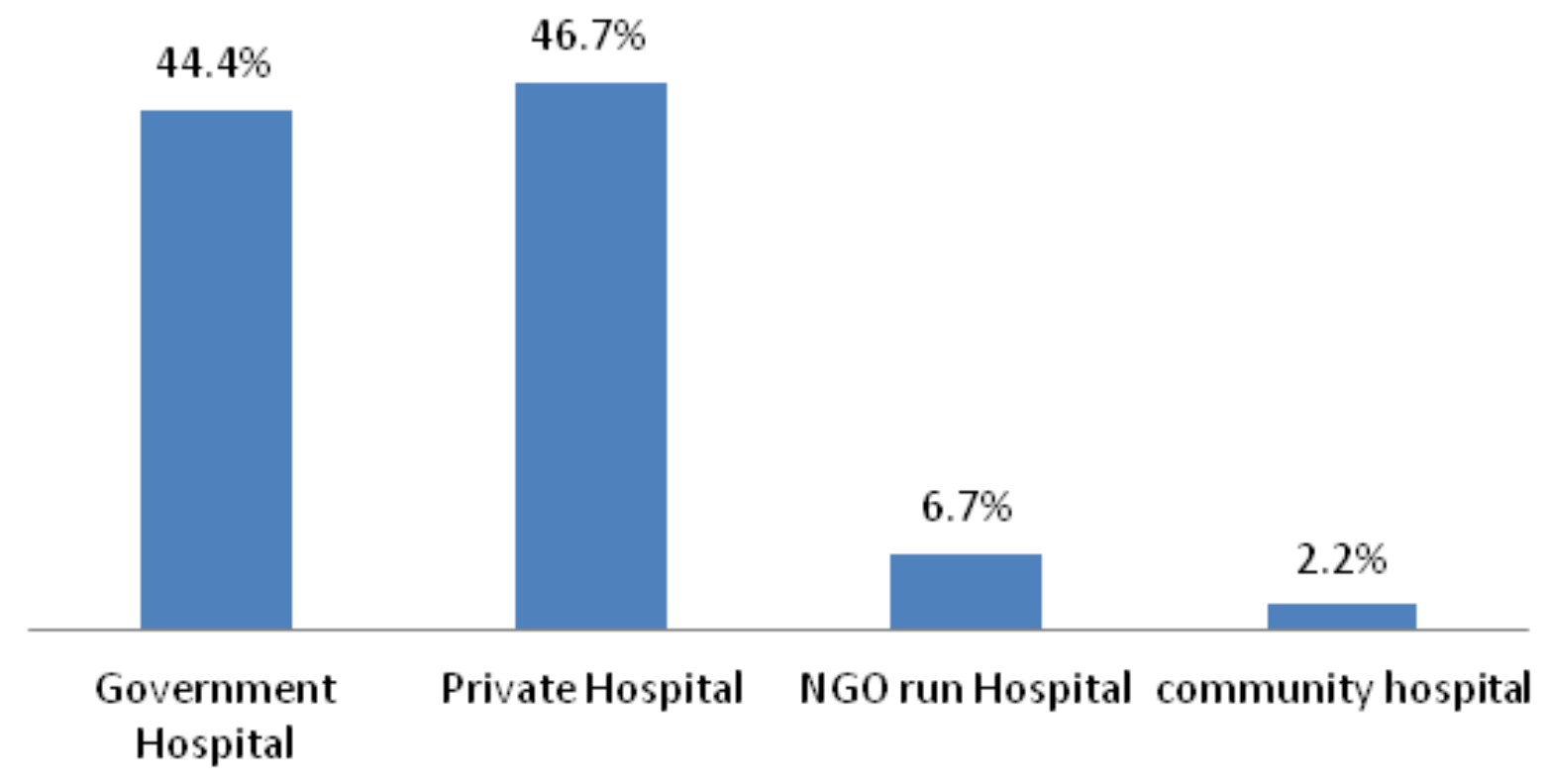

Figure 1. Graph illustration the place of practice of the physicians.

\section{Knowledge about eye examination for diabetes}

All of the physicians(100\%) agreed that patients with type II diabetes should be sent for ophthalmic evaluations with $87 \%$ of them mandating an immediate evaluation after the diagnosis. In contrast, in type, I diabetes,Forty-one (91\%)of the physicians thought ophthalmic evaluation to be important with $58 \%$ of the physicians agreeing that the first evaluations should be done immediately after the diagnosis. Thirtynine out of $45(87 \%)$ physicians answered that they would refer their pregnant patients with diabetes to an ophthalmologist for evaluation (Table1) 
Table 1. Physicians Knowledge on Diabetes and screening for Diabetic retinopathy

\begin{tabular}{|l|l|l|l|l|}
\hline Type of Diabetes & $\begin{array}{l}\text { Type I } \\
\text { Diabetes }\end{array}$ & $\begin{array}{l}\text { Type II } \\
\text { Diabetes }\end{array}$ & $\begin{array}{l}\text { Gestat } \\
\text { ional }\end{array}$ & $\begin{array}{l}\text { All Patients of } \\
\text { Diabetes }\end{array}$ \\
\hline $\begin{array}{l}\text { Should be referred to an } \\
\text { Ophthalmologist (Agreement) }\end{array}$ & & & & \\
\hline Yes & $41(91 \%)$ & $45(100 \%)$ & $\begin{array}{l}39(87 \\
\%)\end{array}$ & $41(91 \%)$ \\
\hline No & $4(9 \%)$ & & $5(11 \%)$ & $3(7 \%)$ \\
\hline Don't Know & & & $1(2 \%)$ & $1(2 \%)$ \\
\hline & & & & \\
\hline When to Refer & & & & \\
\hline Immediately after diagnosis & $26(58 \%)$ & $39(87 \%)$ & NA & NA \\
\hline After 6months & $8(18 \%)$ & $4(9 \%)$ & NA & NA \\
\hline After 1 year & $7(15 \%)$ & $2(4 \%)$ & NA & NA \\
\hline
\end{tabular}

All of the physicians $(100 \%)$ were aware of the fact that diabetes can damage the eye and can cause impairment in vision. Eleven(24.4\%) of them identified retinopathy alone as a complication of diabetes while thirty-four $(85.6 \%)$ identified that diabetes could cause a refractive error, cataract, glaucoma and diabetic retinopathy. When queried about the treatment options for diabetic retinopathy, majority 25(55\%) pointed laser therapy as the only possible treatment followed by intravitreal agents $10(22 \%)$. (Table 2 ) 
Table 2 Physicians knowledge on Diabetic retinopathy, its potential ocular manifestations, and

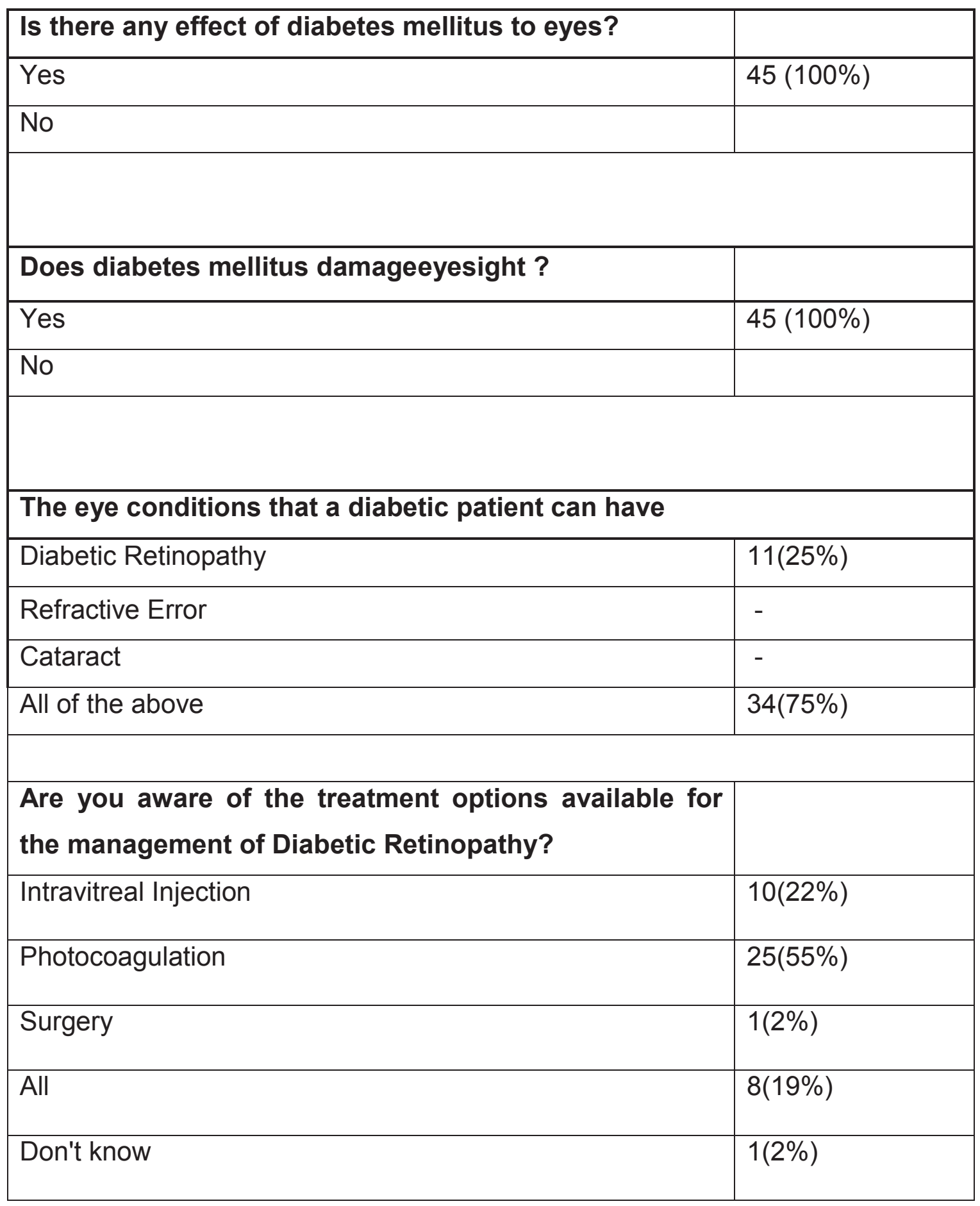


Table 3. Physicians' attitude regarding diabetic retinopathy

\begin{tabular}{|l|l|l|l|l|}
\hline Attitude & Disagree & Neutral & Agree & $\mathrm{p}$-value \\
\hline $\begin{array}{l}\text { An eye examination is needed only when } \\
\text { vision is affected }\end{array}$ & $44(98 \%)$ & - & $1(2 \%)$ & $\mathrm{P}<0.001$ \\
\hline $\begin{array}{l}\text { When diabetes is well controlled, there is } \\
\text { no need to be concerned about diabetic } \\
\text { retinopathy }\end{array}$ & $37(82 \%)$ & $3(7 \%)$ & $5(11 \%)$ & $\mathrm{P}<0.001$ \\
\hline $\begin{array}{l}\text { If the disease is treated early on, diabetic } \\
\text { retinopathy can be prevented/ delayed }\end{array}$ & $1(2 \%)$ & $2(4 \%)$ & $42(94 \%)$ & $\mathrm{P}<0.001$ \\
\hline
\end{tabular}

\section{Attitudes}

$98 \%$ of physicians disagreed that eye examination was required only once the vision was affected. $82 \%$ agreed that despite a good glycemic control, screening for diabetic retinopathy should still be performed and $94 \%$ of them agreed that if diabetes was treated early, diabetic retinopathy and its complications could be prevented or delayed $(\mathrm{p}<0.001)($ Table 3$)$

\section{Practices of retinal examination of diabetics}

$56 \%$ of the physicians said they routinely perform direct ophthalmoscopy to examine the retina (p 0.551). However, among them, nearlyhalf (44\%) didn't know the importance of dilating the pupil for $(\mathrm{p}=0.69)$. Only $49 \%$ of participants said they refer six monthly for an eye examination.(Figure 2) $64 \%$ of the participant said that they refer pregnant diabetic patients for eye examination $(\mathrm{p}=0.072) .11 \%$ of the participants said that they did not need to worry about ocular complications when blood sugar is well controlled. In regards to the barrier for screening, the factors were lack of exposure $(53 \%)$, lack of adequate time (42\%), both $(5 \%)(\mathrm{P}<0.001)$. (Table 4)

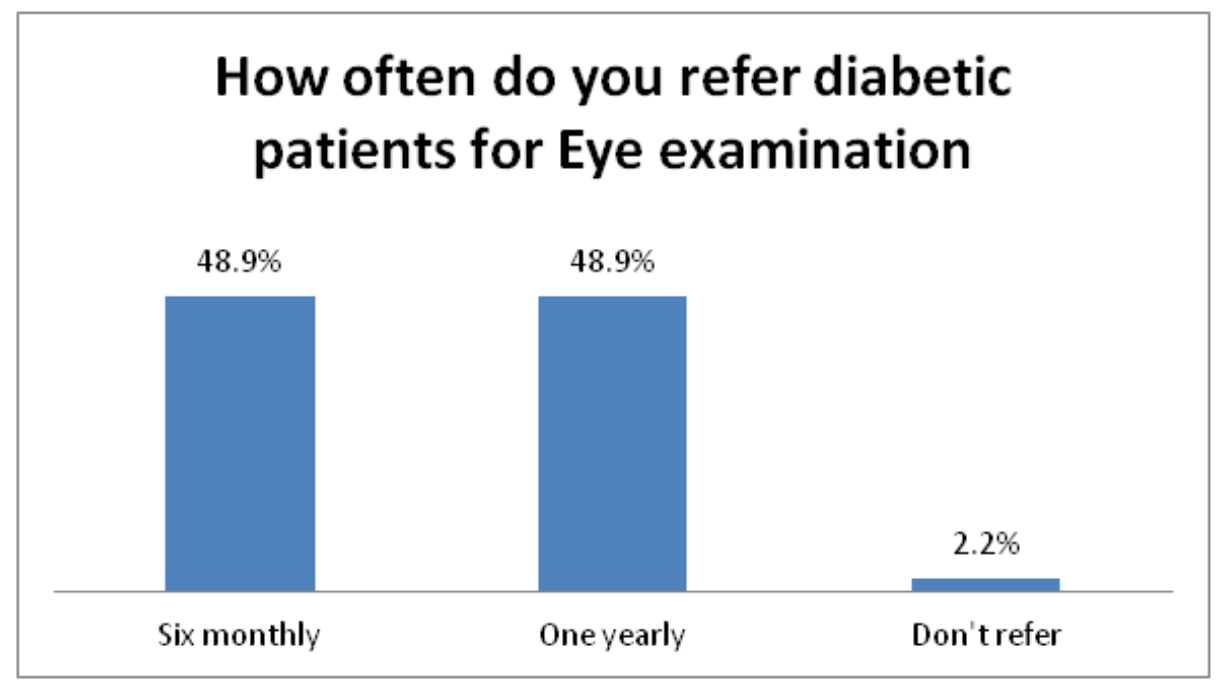

Figure 2. Graph eliciting the frequency of follow-ups that the physicians recommend to their diabetic patients. 
Table 4. Physicians practice for screening and ocular examination for diabetic eye changes in their patients

\begin{tabular}{|c|c|c|}
\hline $\begin{array}{l}\text { Do you perform Ophthalmoscopy to } \\
\text { examine fundus? }\end{array}$ & & \multirow[b]{3}{*}{$p=0.551$} \\
\hline Yes & $25(56 \%)$ & \\
\hline No & $20(44 \%)$ & \\
\hline \multicolumn{2}{|l|}{$\begin{array}{l}\text { If You answered yes, do you dilate the } \\
\text { pupil }\end{array}$} & \multirow{3}{*}{$p=0.69$} \\
\hline Yes & $14(56 \%)$ & \\
\hline No & $11(44 \%)$ & \\
\hline \multicolumn{2}{|l|}{$\begin{array}{l}\text { Do you refer a pregnant diabetic patient } \\
\text { for an eye check up }\end{array}$} & \multirow[b]{3}{*}{$P=0.072$} \\
\hline Yes & $29(64 \%)$ & \\
\hline No & $16(36 \%)$ & \\
\hline \multicolumn{2}{|l|}{ Frequency of referring } & \multirow{6}{*}{$p=0.017$} \\
\hline First Trimester & $7(15 \%)$ & \\
\hline Second Trimester & $7(15 \%)$ & \\
\hline Third Trimester & $3(8 \%)$ & \\
\hline All & $14(31 \%)$ & \\
\hline Do not refer & $14(31 \%)$ & \\
\hline \multicolumn{2}{|l|}{$\begin{array}{l}\text { The reason for not having Retinopathy } \\
\text { screening at your practice }\end{array}$} & \multirow[b]{4}{*}{$P<0.001$} \\
\hline Lack of time & $19(42 \%)$ & \\
\hline Lack of training & $24(53 \%)$ & \\
\hline all the above & $2(5 \%)$ & \\
\hline
\end{tabular}


Diabetic Eye Disease Related KAP among Physicians...

Jour of Diab and Endo Assoc of Nepal 2018; 2 (2):(26-36)

ISSN Print 2594-3367

ISSN Online 2631-2107

\section{Discussion:}

Diabetic retinopathy often damages the retina and can trigger a series of cascading effects, which can result in full vision loss. Screening can catch this disease before irreparable damage is done. DR is a specific microvascular complication of DM and affects 1 in 3 persons with DM. ${ }^{29}$ Most protocols agree that the patients with type 2 diabetes mellitusshould receive screening first eye examination at the time of diagnosis and must undergo a dilated fundus examination to rule out evidence of diabetic retinopathy by an ophthalmologist. ${ }^{30}$ DR develops with time and is associated with poor control of blood sugar, blood pressure, and blood lipids.

The longer someone has had DM, and the poorer their control, the higher their risk of developing DR. ${ }^{31}$ Our study found that all of the physicians agreed that patients with type II diabetes should be sent for ophthalmic evaluations with $87 \%$ agreeing on an immediate evaluation after the diagnosis. In contrast, in type, I diabetes, $91 \%$ of the physicians thought ophthalmic evaluation to be important with $58 \%$ of the physicians agreeing that the first evaluations should be done immediately after the diagnosis. Vision-threatening retinopathy is rare in type 1 diabetic patients in the first 3-5 years of diabetes or before puberty. During the next two decades, nearly all type 1 diabetic patients develop retinopathy. Up to $21 \%$ of patients with type 2 diabetes have retinopathy at the time of the first diagnosis of diabetes, and most develop some degree of retinopathy over time. ${ }^{31}$

In this study, majority of the physicians answered that they would refer their pregnant patients with diabetes to an ophthalmologist for evaluation. Approximately $12 \%$ of women with no retinopathy at the start of pregnancy will develop mild retinopathy consisting of a microaneurysm but regression after delivery is usually the rule. ${ }^{32,33}$

However, there is a certain group which can have a very aggressive variant mandating urgent pan- retinal photocoagulation (PRP) to slow down the progression. ${ }^{34}$

All of the physicians were found to have awareness that diabetes can damage the eye and can cause impairment in vision. Majority of the physicians were found to have knowledge of the effect of DM that there are other structures besides retina that can be affected but it was worrying that nearly quarter of the physicians identified DR as the only possible ocular complication of DM. Physicians were also found to have inadequate knowledge regarding management of diabetic. More than half answered laser as the only modality. In today's anti-VEGF era, only around a quarter were able to identify it as one of the major treatment options. This could possibly due to lack of update of GP's on the management of DR.

The general rule now for screening for DR is that even if there is little or no evidence of DR, with normal or near-normal visual acuity and with good glycemic control at the initial time of evaluation. Persons with diabetes should have an annual eye examination. ${ }^{31}$ The U.K. Prospective Diabetes Study (UKPDS) demonstrated that for every percentage point decrease in $\mathrm{HbAlc}$, there was nearly $35 \%$ reduction in the risk of microvascular complications. Almost all of the physicians in our study agreed that glycemic control could slow down the progression but the patients should still be screened for DR at least on a yearly basis. They also acknowledged that vision impairment could be slowed or prevented if the patients with diabetic retinopathy are treated early.

This study also shows the need for training of physicians, general practitioners (GPs) and endocrinologists about diabetic retinopathy and its detection with a direct ophthalmoscope. Our study found that nearly half of them do not perform ophthalmic examinations and from those who do perform it, again, nearly half of them do not perform fundus examination under dilatations. Our study points that there needs urgent addressing regarding the importance of fundus examination 
Diabetic Eye Disease Related KAP among Physicians...

Jour of Diab and Endo Assoc of Nepal 2018; 2 (2):(26-36)

and the need for a dilated eye examination. One of the factors could be due to lack of mydriatic agents and lack of confidence in detecting changes even when examining dilated eyes. Knowledge of the guidelines of screening and management of diabetic retinopathy is another important factor to be considered. Bachelor and Residency programs should focus on providing the importance of ophthalmic examinations for detection of DR and also exposure to ophthalmoscopy.

The response from the doctors on screening for DR during pregnancy received a mixed practice pattern. Nearly $1 / 3$ rd of the doctors never sent their patient for DR screening or think it is necessary to be done irrespective of the gestation period. The knowledge that "Diabetic patient with pregnancy and gestational diabetes" has a different pathology, disease course and outcomes seems to require more robust dissemination. Most of the physicians also agreed on this regard as more than 50 percent of them agreed that their current trend in practicing diabetic eye care is mostly due to lack of training in performing eye screening for diabetic retinopathy.

\section{Conclusion}

The study shows a good level of diabetic retinopathy awareness and knowledge with relatively positive attitudes toward the importance of diabetes care. At the same time, it has found that practice level despite good knowledge and attitude to be below average among the physicians who are managing diabetic patients.

There is a need to carry out large-scale awareness programs, after identifying the appropriate means to spread the message mainly focusing on the protocols, examination techniques and updates regarding various approaches of managing a potential case of diabetic retinopathy. There is also a requirement for practice to be improved by the supplementing adequate information, increasing the availability of educational materials, proper guidance, and training among physicians who are managing diabetic patients.

\section{REFERENCES:}

1. Global report on diabetes.World Health Organization.ISBN 9789241565257 (NLM classification: WK 810)(website (http://www. who.int )(Accessed Date Jan 2018).

2. Zheng Y, He M, Congdon N. The worldwide epidemic of diabetic retinopathy. Indian Journal of Ophthalmology. 2012;60(5):428431. doi:10.4103/0301-4738.100542.

3. IDF DIABETES ATLAS Eighth edition 2017 .Online version of IDF Diabetes Atlas: www. diabetesatlas.org ISBN: 978-2-930229-87-4) (Accessed Date: Dec 2018).

4. Mohamed Q, Gillies MC, Wong TY. Management of diabetic retinopathy: A systematic review. JAMA 2007;298:902-16.

5. Rema M, Premkumar S, Anitha B, Deepa R, Pradeepa R, Mohan V, et al. Prevalence of diabetic retinopathy in urban India: The Chennai urban rural epidemiology study (CURES) eye study, I. Invest Ophthalmol Vis Sci 2005;46:2328-33. Back to cited text no. 1.

6. Field M, Lohr K. Clinical Practice Guidelines: Directions for a New Program. National Academy Press, Washington, DC, USA (1992.

7. The Diabetic Retinopathy Study Research Group. Photocoagulation treatment of proliferative diabetic retinopathy. Clinical application of Diabetic Retinopathy Study (DRS) findings, DRS Report Number 8. Ophthalmology 88(7), 583-600 (1981).

8. Early Treatment Diabetic Retinopathy Study Research Group. Early photocoagulation for diabetic retinopathy. ETDRS report number 9. Ophthalmology 98(Suppl. 5), 766-785 (1991).

9. Friedman DS, Ali F, Kourgialis N. Diabetic retinopathy in the developing world: how to approach identifying and treating underserved populations. Am. J. Ophthalmol. 151(2), 192194.e1 (2011).

10. Khatri A, Shrestha JK, Thapa M, Khatri BK, Kharel M. Severity of primary open-angle glaucoma in patients with hypertension and diabetes. Diabetes, Metabolic Syndrome and Obesity: Targets and Therapy. 2018;11:209- 
Diabetic Eye Disease Related KAP among Physicians...

Jour of Diab and Endo Assoc of Nepal 2018; 2 (2):(26-36)

\section{5. doi:10.2147/DMSO.S160978.}

11. Okamoto $F$, Sone $H$, Nonoyama $T$, et al Refractive changes in diabetic patients during intensive glycaemic control British Journal of Ophthalmology 2000;84:1097-1102.

12. Andreas Pollreisz and Ursula SchmidtErfurth, "Diabetic Cataract-Pathogenesis, Epidemiology and Treatment," Journal of Ophthalmology, vol. 2010, Article ID 608751, 8 pages, 2010. https://doi. org/10.1155/2010/608751.

13. Abdulsalam S, Ibrahim A, Saidu H, Muazu M, Aliyu U T, Umar H I, Gezawa I D, Owolabi L F. Knowledge, attitude, and practice of diabetic retinopathy among physicians in Northwestern Nigeria. Niger J Clin Pract 2018;21:478-83.

14. Diabetic retinopathy (DR): management and referral. Community Eye Health. 2015;28(92):70-71.

15. Negretti, G., Amin, R.D., Webster, L.C., \& Egan, C.A. (2016). Does delay in referral of proliferative diabetic retinopathy from the diabetic eye screening programme lead to visual loss? Eye, 30, 873-876.

16. Saleem M. The impact of delay in diabetic patient's referral for diabetic retinopathy screening on the level of retinopathy detected in adult Sudanese diabetic Sudanese patients. Albasar Int J Ophthalmol 2017;4:49-53.

17. Vengadesan N,Ahmad M, Sindal MD, Sengupta S. Delayed follow-up in patients with diabetic retinopathy in South India: Social factors and impact on disease progression. Indian Journal of Ophthalmology. 2017;65(5):376-384. doi:10.4103/ijo.IJO_620_16.

18. Kaliyaperumal K. Knowledge, attitude and practice study on diabetes and diabetic retinopathy among medical practitioners in southern India. In: 2006 AECS Illumination, vol. VI, No. 2, April - June 2006.

19. R. Khandekar, S. Shah, Lawatti J. Al Retinal examination of diabetic patients: Knowledge, attitudes and practices of physicians in Oman East Mediterr Health J, 14 (2008), pp. 850857.

20. C. Delorme, H.M. Boisjoly, L. Baillargeon, P.
Turcotte, P.M. Bernard Screening for diabetic retinopathy. Do family physicians know the Canadian guidelines? Can Fam Phys, 44 (1998), pp. 1473-1479.

21. R.C. Preti, F. Saraiva, J.A. Junior, W.Y. Takahashi,M.E. daSilvaHowmuch information do medical practitioners and endocrinologists have about diabetic retinopathy? Clinics, 62 (3) (2007), pp. 273-278.

22. Michael N. Wiggins, Reid D. Landes, Swetangi D. Bhaleeya, et al. Primary care physicians' knowledge of the ophthalmic effects of diabetes Can J Ophthalmol, 48 (11) (2013), pp. 265-268.

23. J.S. Muecke, H.S. Newland, P. Ryan, E. Ramsay, M. Aung, S. Myint, et al. Awareness of diabetic eye disease among general practitioners and diabetic patients in Yangon, Myanmar Clin Exp Ophthalmol, 36 (3) (2008), pp. 265-273.

24. F. Wang, J.C. Javitt Eye care for elderly Americans with diabetes mellitus: failure to meet current guidelines.

25. Upadhyay D, Palaian S, Shankar P, Mishra P. Knowledge, Attitude and Practice about diabetes among diabetes patients in Western Nepal. Rawal Med J. 2008;33:8-11.

26. Gautam A, Bhatta DN, Aryal UR. Diabetes related health knowledge, attitude and practice among diabetic patients in Nepal. BMC endocrine disorders. 2015;15:25.

27. Thapa $\mathrm{R}$ et al Demographics and awareness of diabetic retinopathy Nepal J Ophthalmol 2012; 4(7):10-16.

28. Kaliyaperumal K. Guidelines for conducting a knowledge, attitude and practice study. AECS Illumination. 2004;4(1):7-9.

29. Klein R, Klein BE, Moss SE, Davis MD, DeMets DL: The Wisconsin Epidemiologic Study of Diabetic Retinopathy. III. Prevalence and risk of diabetic retinopathy when age at diagnosis is 30 or more years. Arch Ophthalmol 102: 527-532, 1984. 
30. Donald S. Fong, Lloyd Aiello, Thomas W. Gardner, George L. King, George Blankenship, Jerry D. Cavallerano, Fredrick L. Ferris, Ronald Klein Diabetes Care Jan 2004, 27 (suppl 1) s84-s87; DOI: 10.2337/diacare.27.2007.S84.

31. Batchelder T, Barricks M: The Wisconsin Epidemiologic Study of Diabetic Retinopathy (Letter) Arch Ophthalmol 113: 702-703, 1995.

32. Sunness JS (1988) The pregnant woman's eye. Surv Ophthalmol 32:219-238.
33. Serup L(1994) Influence of pregnancy on diabetic retinopathy. Acta Endocrinol 27 (Suppl 1986) 122-124.

34. Conway M, Baldwin J, Kohner EM, Schulenburg WE, Cassar J(1991) Postpartum progression of diabetic retinopathy. Diabetes Care 14:1110-1111. 